\section{NYBOMYCIN. V \\ TOTAL SYNTHESIS OF NYBOMYCIN ${ }^{1)}$}

Sir :

The antibiotic nybomycin was isolated several years ago in two laboratories from streptomyces cultures. ${ }^{2,3)}$ It has strong antibacterial activity against Gram-positive and some Gram-negative organisms, as well as antifungal and antiphage activity, but its insolubility hinders its in vivo utility. ${ }^{2,4)}$ We very recently assigned structure 1 to nybomycin ${ }^{5)}$, revising a previously assigned formula ${ }^{6}$. We report here an unambiguous total synthesis of 6,11-dimethyl-8-hydroxymethyl-4, 10-dioxo- $2 \mathrm{H}, 4 \mathrm{H}, 10 \mathrm{H}, 11 \mathrm{H}$-pyrido [3,2-g]-oxazolo[5,4,3-ij]quinoline (1) and its complete identity with nybomycin.

The key intermediate in our synthetic scheme was deemed to be 2 , with its disparate terminal rings, a compound prepared earlier in our recently reported total synthesis of deoxynybomycin $(3)^{1)}$. If the pyridine $\gamma$-methyl group (8-methyl of 2) could be oxidized selectively in the presence of the pyridone $\gamma$-methyl group (6-methyl of 2 ), then the procedure employed for the synthesis of deoxynybomycin could be adapted readily to the preparation of nybomycin. Accordingly, studies with model compounds were initiated. These revealed that the methyl group in lepidine (4) could be oxidized to an aldehyde by freshly prepared selenium dioxide in refluxing dioxane ${ }^{7}$, giving $5\left(\mathrm{C}_{10} \mathrm{H}_{7} \mathrm{NO},{ }^{*},{ }^{\dagger}\right.$ m.p. $\left.48 \sim 50^{\circ} \mathrm{C}\right)$ in $52 \%$ yield. Under the same conditions the methyl group of $\mathbf{6}$ was unaffected and to oxidize it to an aldehyde required fusion with selenium dioxide at $175^{\circ} \mathrm{C}$ for 1.25 hours ${ }^{8)}$.

Conversion of 4 to the model quinolone 7 continued with the reduction of $\mathbf{5}$ by sodium borohydride ${ }^{9)}$ in ethanol to $8\left(\mathrm{C}_{10} \mathrm{H}_{9} \mathrm{NO}\right.$, m.p. $\left.93 \sim 95^{\circ} \mathrm{C}, 86 \%\right){ }^{*}, \dagger$ Methylation of 8 with an equivalent amount of dimethyl sulfate in refluxing benzene gave its methosulfate salt, which was oxidized in aqueous media with potassium hydroxide and potassium ferricyanide ${ }^{10)}$ at $3^{\circ} \mathrm{C}$ for 6 hours; however,
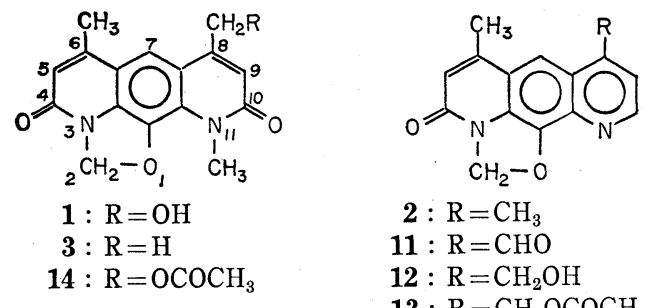

2: $\mathrm{R}=\mathrm{CH}_{3}$

$11: \mathrm{R}=\mathrm{CHO}$

12: $\mathrm{R}=\mathrm{CH}_{2} \mathrm{OH}$

$13: \mathrm{R}=\mathrm{CH}_{2} \mathrm{OCOCH}_{3}$
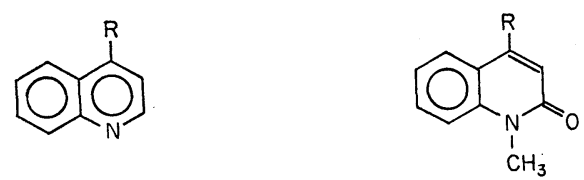

4: $\mathrm{R}=\mathrm{CH}_{3}$
$5: \mathrm{R}=\mathrm{CHO}$
8: $\mathrm{R}=\mathrm{CH}_{2} \mathrm{OH}$
9: $\mathrm{R}=\mathrm{CH}_{2} \mathrm{OCOCH}_{3}$

6: $\mathrm{R}=\mathrm{CH}_{3}$

7: $\mathrm{R}=\mathrm{CH}_{2} \mathrm{OH}$

$10: \mathrm{R}=\mathrm{CH}_{2} \mathrm{OCOCH}_{3}$

the product mixture gave a positive test with 2,4-dinitrophenylhydrazine, indicating that oxidation of the hydroxymethyl group of 8 to an aldehyde had occurred. The hydroxyl group of 8 was, therefore, protected by acetylation in glacial acetic acid containing a trace of sulfuric acid at $100^{\circ} \mathrm{C}$. The acetate, $9\left(\mathrm{C}_{12} \mathrm{H}_{11} \mathrm{NO}_{2}\right.$, m.p. $55 \sim 58^{\circ} \mathrm{C}$, $72 \%),{ }^{*+}$ was then converted by methylation to its methosulfate and oxidized as before, to give $10\left(\mathrm{C}_{13} \mathrm{H}_{13} \mathrm{NO}_{3} \text {, m.p. } 157 \sim 159^{\circ} \mathrm{C}\right)^{*, \dagger}$ in $31 \%$ yield. The quinolone ester 10 was hydrolyzed in $0.5 \mathrm{~N}$ ethanolic potassium hydroxide at reflux for 0.5 hour to afford $7\left(\mathrm{C}_{11} \mathrm{H}_{11} \mathrm{NO}_{2}\right.$, m.p. $\left.185 \sim 187^{\circ} \mathrm{C}, 74 \%\right){ }^{*, \dagger}$

Employing the reaction sequence and reagents developed for preparation of the model compound 7,2 was selectively oxidized to the formyl derivative $11\left(\mathrm{C}_{15} \mathrm{H}_{10} \mathrm{~N}_{2} \mathrm{O}_{3}\right.$, m.p. $278 \sim 280^{\circ} \mathrm{C}, 53 \%$ ), ${ }^{*},+,+t$ which was reduced to the hydroxymethyl analog $12\left(\mathrm{C}_{15}\right.$ -

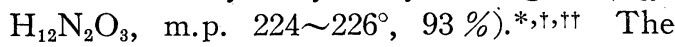
latter compound was subsequently acetylated to give $13\left(\mathrm{C}_{17} \mathrm{H}_{14} \mathrm{~N}_{2} \mathrm{O}_{4}\right.$, m.p. $248 \sim 250^{\circ}$, $63 \%),{ }^{*,+, \dagger \dagger}$ which was methylated then oxidized with potassium hydroxide and potassium ferricyanide to give $\mathbf{1 4}\left(\mathrm{C}_{18} \mathrm{H}_{16} \mathrm{~N}_{2} \mathrm{O}_{5}\right)^{*,+, \dagger \dagger}$ in $18 \%$ yield (from 13 ).

The synthetic sample of $\mathbf{1 4}$ was identical with an authentic sample of nybomycin acetate, prepared from nybomycin by the method of EBLE, et $a l . .^{3)}$, in m.p. $\left(234 \sim 236^{\circ} \mathrm{C}\right)$,

\footnotetext{
* Microanalyses agree with the molecular formula shown.

† Low resolution mass spectral data agree with the molecular formula shown.

t† High resolution mass spectral data agree with the molecular formula shown.
} 
thin-layer chromatographic behavior, infrared spectrum $(\mathrm{KBr})$, nmr spectrum (trifluoroacetic acid), and mass spectrum. An intimate mixture of the synthetic and authentic samples of 14 melted at $233 \sim 235^{\circ} \mathrm{C}$. Basic hydrolysis of synthetic 14 was effected in $73 \%$ yield. The product $\left(1, \mathrm{C}_{16} \mathrm{H}_{14} \mathrm{~N}_{2} \mathrm{O}_{4}\right.$, m.p. $\left.>350 \mathrm{C}^{\circ}\right),{ }^{*},+$ was identical with authentic nybomycin in thin-layer chromatographic behavior, as well as infrared $(\mathrm{KBr}), \mathrm{nmr}$ (trifluoroacetic acid), and mass spectra.

\section{Acknowledgements}

This work was supported in part by Public Health Service grants, AI 01278 and AI 04769, from the National Institute of Allergy and Infectious Diseases.

\author{
Richard M. Forbis* \\ Kenneth L. Rinehart, Jr. \\ Department of Chemistry \\ University of Illinois \\ Urbana, Illinois 61801, U.S.A. \\ * National Science Foundation \\ Predoctoral Fellow.
}

(Received February 10, 1971)

\section{References}

1) Preceding paper in this series:

Forbis, R. M. \& K. L. Rinehart, Jr.: Nybomycin. IV. Total synthesis of deoxynybomycin. J. Amer. Chem. Soc. 92 : 6995, 1970
2) Strelitz, F.; H. Flon \& I. N. Asheshov: Nybomycin, a new antibiotic with antiphage and antibacterial properties. Proc. Natl. Acad. Sci. U. S. $41: 620 \sim 624,1955$

3) Eble, T. E.; G. A. Boyack, C. M. Large \& W. H. DeVries: Nybomycin: isolation, properties, and derivatives. Antibiot. Chemotherapy $8: 627 \sim 630,1958$

4) BRock, T. D. \& W. T. Sokolski: Biological studies on the antibiotic nybomycin. Antibiot. Chemotherapy $8: 631 \sim 636,1958$

5) Rinehart, Jr., K. L.; G. Leadbetter, R. A. Larson \& R. M. Forbis: Nybomycin. III. A revised structure. J. Amer. Chem. Soc. $92: 6994,1970$

6) Rinehart, Jr., K. L. \&. H. B. Renfroe: The structure of nybomycin. J. Amer. Chem. Soc. $83: 3729 \sim 3730,1961$

7) Kaplan, H.: The use of selenium dioxide in the preparation of quinoline aldehydes: J. Amer. Chem. Soc. $63: 2654 \sim 2655,1941$

8) Соoк, D. J. \& M. Stamper : 1-Methy1-4carbostyrilcarboxaldehyde and certain condensation products. J. Amer. Chem. Soc. 69 : 1467〜1468, 1947

9) Chaikin, S. W. \& W. G. Brown: Reduction of aldehydes, ketones and acid chlorides by sodium borohydride. J. Amer. Chem. Soc. $71: 122 \sim 125,1949$

10) Prill, E. A. \& S. M. McElvain: 1-Methyl2-pyridone. pp. $419 \sim 421$

In A. H. Bцатт (ed.), Organic Syntheses, Coll. Vol. II, John Wiley \& Sons, Inc., New York, 1943 